\title{
Article
}

\section{A critical analysis of J.C. Smuts' theory of holism}

Jörgenfelt, Chris and Partington, Hazel

Available at http://clok.uclan.ac.uk/29968/

Jörgenfelt, Chris and Partington, Hazel ORCID: 0000-0003-3566-7035 (2019) A critical analysis of J.C. Smuts' theory of holism. European Journal of Integrative Medicine, 31 . p. 100980. ISSN 1876-3820

It is advisable to refer to the publisher's version if you intend to cite from the work. http://dx.doi.org/10.1016/j.eujim.2019.100980

For more information about UCLan's research in this area go to http://www.uclan.ac.uk/researchgroups/ and search for <name of research Group>.

For information about Research generally at UCLan please go to http://www.uclan.ac.uk/research/

All outputs in CLoK are protected by Intellectual Property Rights law, including Copyright law. Copyright, IPR and Moral Rights for the works on this site are retained by the individual authors and/or other copyright owners. Terms and conditions for use of this material are defined in the policies page.

\section{CLoK}

Central Lancashire online Knowledge www.clok.uclan.ac.uk

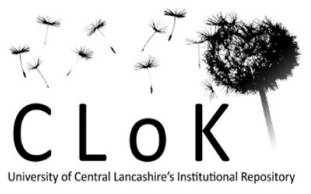




\section{Journal Pre-proof}

A critical analysis of Smuts' theory of holism

Chris Jörgenfelt, Hazel Partington

PII:

S1876-3820(18)31006-0

DOI:

https://doi.org/10.1016/j.eujim.2019.100980

Reference:

EUJIM 100980

To appear in:

European Journal of Integrative Medicine

Received Date:

19 December 2018

Revised Date:

20 August 2019

Accepted Date:

15 September 2019

Please cite this article as: Jörgenfelt C, Partington $\mathrm{H}, \mathrm{A}$ critical analysis of Smuts' theory of holism, European Journal of Integrative Medicine (2019),

doi: https://doi.org/10.1016/j.eujim.2019.100980

This is a PDF file of an article that has undergone enhancements after acceptance, such as the addition of a cover page and metadata, and formatting for readability, but it is not yet the definitive version of record. This version will undergo additional copyediting, typesetting and review before it is published in its final form, but we are providing this version to give early visibility of the article. Please note that, during the production process, errors may be discovered which could affect the content, and all legal disclaimers that apply to the journal pertain.

(C) 2019 Published by Elsevier. 


\section{A critical analysis of Smuts' theory of holism}

Chris Jörgenfelt, MSc \& Dr Hazel Partington

Contact person:

Chris Jörgenfelt, Gopshus bygata 15, 79294 Mora

Sweden

chris.jorgenfelt@gmail.com

Dr. Hazel Partington

Room 323

Brook Building

The University of Central Lancashire

Preston Lancashire

PR1 2HE

hpartington@uclan.ac.uk

\section{Abstract}

Introduction: Due to the lack of a clear definition, the word holism has become a vague and inexplicit concept open for uncertain interpretations. In view of the increasing interest in holistic medicine and holistic healthcare solutions, as well as the frequent labelling of non-reductive research models as holistic, a more specific definition of holism is essential to enable a structured foundation of the concept.

Method: In order to reach a more explicit definition of the word holism, an integrative literature review methodology was utilised to critically analyse J.C. Smuts original theory of holism as presented in his book 'Holism and Evolution'.

Result: The results point to a diverted theory with one part presenting an advanced view of the physicality of reality, while the second part lacks a logical foundation.

Conclusion: In line with current biological systems theories and neurological research, a new definition of holism is suggested, taking into consideration the element of evolution through a mainly intrinsic process, with an emphasis on individual abilities of self-maintenance and resilience towards the impact of psychosocial stressors.

Keywords: Holism, Smuts, evolution, wholes, fields, space-time 


\title{
Introduction
}

\begin{abstract}
"Quantum holism is different from the sort of holism that Cartesian philosophy of physics admits."
\end{abstract}

Michael Esfeld [1]

The increasing popularity of the word holism, and its derivate holistic, indicates a general striving in a rising number of scientific fields to reduce the influence of reductive research models and replace them with non-linear systems-based structures. A perspective defined as holistic can comprise all levels, from cell interaction to placing living beings in a universal theory of reality, as each step creates a wider picture of a complex system. Commonly holism is equated with a non-reductive approach [2,3], but this definition is too vague and leaves the field open for uncertain interpretations, resulting in a loss of meaning [4-9]. With current usage, the word holism seems to have become a floating signifier, lacking reflection of the original definition of the word $[5,6,8,10]$. As an indication of the phenomenon, the 200 first articles identified by a search on Google Scholar for 'definition holism' since 2012, represented 36 different scholarly areas using the word holism to describe their research. Quantum holism, holistic ecology, holistic engineering, holistic biology, linguistic holism, management holism and holistic medicine are some examples of the word holism indicating more complex scientific models. In order to reach a more explicit definition a critical analysis was made of Jan Christian Smuts' theory of holism from 1926 [11]. The theory was chosen as the original theory presenting holism and its expanded concepts relating to physics are still not falsified.

\section{Methodology}

This paper reports an integrative literature review (ILR) [12]. The methodology is considered appropriate for acquiring an overview over large amounts of data as well as creating a further understanding of an emerging topic, investigating contradictory evidence and bridging research from different fields [13]. Additionally, by combining existing concepts with new ideas, the ILR methodology enables the identification of gaps in research $[14,15]$.

In keeping with Cronin et al.'s. prediction of the complexity involved in evaluating non-reviewed publications [16], Smuts' presentation of his theory in 'Holism and Evolution' was not easy to approach. Smuts introduces a large number of new concepts, however, the explanations of 
these concepts are presented in a scattering throughout the book, rather than in a structured manner with separate chapters to explain each concept and show the development of his ideas. Iterative analysis was used to identify and organise significant quotes from different chapters of Smuts' book into themes, which were subsequently organised into categories. This methodology is comparable with a qualitative content analysis [17-19]. The development of an initial thematic framework was thus based on immersion in Smuts' work and as an interpretive approach was continually revised as new themes emerged from the text [20].

From an initial reading, categories were constructed to cover the theory:

- Holism,

- Wholes,

- The theory of fields,

- The concept of time,

- Matter,

- Evolution,

- Mechanism or reductionism vs holism,

- Mind in the concept of holism,

- Personality as a whole,

- External vs internal reality and intrinsic evolution.

However, during analysis of the four last chapters, multiple contradictions in the theory was striking and demanded two more categories:

- Contradictory and unclear parts of the theory

- Hierarchical view of reality (and its implication on the perception of reality).

Quotes from different chapters in the book were then placed adjacent under each category and the main words from each quote extracted and divided in accordance with Smuts' description of the subject. The final step was to construct the essence of each category into the conclusions presented in the article. This method also made it possible to identify contradictory statements.

\section{A short biography of Smuts}

To understand why the theory was so sprawling a more holistic approach was taken, including Smuts himself in the analysis, in line with his own opinion on analysing literature [21]. An extensive literature search for articles concerning Smuts' political, philosophical and scientific work was conducted in several databases and personal data were integrated into the analysis. Taking Smuts' own history into account made it possible to better understand the alternation in 
his theory between a rare height of intellectual insight on one side and what can only be described as a narrowminded position on the other. This step was key to get a better comprehension of the contradictions in the theory.

Smuts (1870 - 1950) was born on a farm in South Africa. As a student he showed an extraordinary ability for academic work and through a scholarship studied law at Cambridge, becoming one of the most distinguished students ever to have graduated [22,23]. Further academic recognition included an appointment as President of the British Association for the Advancement of Science and an honorary Doctorate [D.Sc.] from London University in 1931 [24]. At the end of his life Smuts was also appointed Chancellor of Cambridge. Smuts always held a strong interest in science and continuously read scientific books and journals, and was accepted as an authority in botanical research of grasses in South Africa [25,26]. However, Smuts is probably best-known for his work in the political field, serving as Prime Minister of South Africa between 1919 - 1924 and 1939 - 1948, as well as being a member of the Imperial War Cabinet of the British Commonwealth during the first and second world war [25]. Although Smuts viewed himself as a humanist, his political decisions, speeches and letters present a picture of a man holding tight to the values of white, European and Christian supremacy [22,23,25-27]. As will be shown, Smuts' cultural values were reflected in his theory and may offer some explanation for his contradictory reasoning when presenting the evolutionary development of mind and personality.

Analysis of Smuts' theory of holism

Smuts aim with 'Holism and Evolution' was "to make a modest contribution towards the reform of the fundamental concepts of matter, life and mind" by transforming the mechanical view of matter as something passive or inert with definite contours into a dynamic concept included in a creative evolutionary process [11].

The book sold well enough to demand a second edition within a year and became part of the ongoing discussions initiated by Darwin's publication of his theory of evolution [28,29]. According to Brush, 'Holism and Evolution' was not well reviewed by the academic journals which might have been due to its critique of the dominant reductive system of science [29]. In his review Morgan pinpoints a weakness in the theory highlighting Smuts' conclusion as failing to find adequate arguments to explain how mindless forms of life like atoms and molecules, living cells, plants and animal embryos are supposed to develop into wholes with mental faculties [28]. He 
also compares Smuts theory with those of esteemed philosopher Henri Bergson and points to Smuts' apparent rejection of the foundation of Bergson's theory although reaching similar conclusions [29]. Available reviews as well as Smuts' supplementary articles in Nature from 1931 indicates that also the merging of science and philosophy was a main topic of discussion [30,31].

In his criticism of holism Popper points to the vagueness of the statement that the whole is more than the sum of its parts and condemns the holistic approach of social scientists as being utopian and totalitarian, as well as incompatible with a scientific attitude. However, his opinion is based on the interpretation of holism made by the scientists and not on a genuine analysis of Smuts' writings [32]. Contemporary reviews of Smuts' theory either ignore the contradictions in the final chapters, or criticise it for being a stillborn theory $[9,10]$. The main impression is that Smuts was too far ahead of his time and the concept of wholes did not become a part of science until Bertalanffy developed the General Systems Theory [33].

\section{Defining holism}

The concept of holism, as presented by Smuts in his theory, is described as "the ultimate principle of the universe", holism being "the operative factor in the evolution of wholes" extending from molecules to humans and including organic as well as inorganic structures [11].

The word holism, coined by Smuts from the Greek word ó of all organisms striving towards transforming passivity into reaction. Through a rising series of coordinating and regulating activities organisms transcend their former structures and reform on a higher level of evolutionary development. In other words, the term holism is equivalent to an inbuilt drive to continue the evolutionary development towards more advanced states, thus creating an increased ability to manage disturbances in the struggles of life.

Creation is described as the driving force behind evolution, and self-creativity the main process behind the transcending progress. Parts transcend themselves by the drive of holism into ever more highly organised wholes with an extended capacity for co-operation and unity. Mechanistic explanations of reality can never describe the process, as every whole is a free and selfdetermining agent in its own active and creative process towards achieving higher levels of wholeness. External stresses or stimulants are processed by individual internal reactions and the result is determined by the stage of the whole in its evolutionary development [11]. 
What constitutes a whole?

A main critique of Smuts' presentation is the lack of structure in the text. Although the concept of wholes is fundamental to the theory, his varied explanations make it difficult to grasp. According to Smuts, the development of wholes is the fundamental nature of reality, constituting a basic tendency of the universe. All wholes are self-creative striving towards greater complexity. The further the evolutionary development of a whole has reached the greater the capacity for independence, ability for self-regulation and self-maintenance are developed. The concept describes a natural progress where the successive phases telescope into each other in such a way that it is hard to discover where one phase ends and the other begins. The description of wholes is in accordance with the biological term emergence, in general referred to as an evolutionary development of whole, complex systems [34-36].

Smuts characterised a whole as containing following properties:

- Individuality

Each organism or organic structure is an individual whole with unique identity and orientation striving toward a more complete wholeness.

- Governed by a mainly intrinsic process

The influence of the environment is only indirect, as the unique character of each whole transforms a similar stressor or disturbance in its own way. Individual levels of attention, ability for selection, willingness to strive against an imposing stimulus and the power of self-regulation and self-maintenance, all parts of individual characters, are factors determining the outcome.

- Marking the timeline of evolution

The self-regulating character of each whole makes the level of plasticity in adjusting and coordinating to stressful situations a marker of its general level of evolutionary development.

- Transcending the parts

The individual capacity for creative solutions transcends the parts and explains why wholes are more than the sum of their parts. Due to a fundamentally unstable equilibrium in nature, instability caused by external impacts will influence all parts and require readjustments of all included elements thus transforming the wholeness. In this two-way system, "the whole is in the parts and the parts are in the whole", with the synthesis reflecting the whole [6]. 


\section{Matter and evolution}

Smuts opposes the mechanistic view of matter, due to its lack of the creative plasticity seen in nature [11]. He points to the ontological corner scientists have painted themselves into by accepting Darwin's natural selection, but still denying the flexibility of nature. Without flexibility, the only way to explain evolution is by pure chance in the form of random mutations. According to Smuts, only holism can explain the creative self-regulating character of the whole, with different levels of adaptability towards disturbances exposed to by the environment.

According to the mechanical view of reality, evolutionary steps are due to an inherent potential that "presupposes that the real creative work is already done, and that the slow finishing touches alone remain to be put on" [11]. A creative evolution is instead based on the internalisation of external stimuli constituting a transformation and resulting in "new quality elements" conditional to individual experiences $[11,27]$. Smuts gives as an example a research experiment by Pavlov where an electric bell rang while white mice were given food. The process had to be repeated 300 times before a firm association was built up for the first generation. Only 150 times were needed to form the connection for the second generation, which decreased to 30 when the third generation was tested. What Smuts tries to explain is today known as epigenetics, the inheritance of behavioral changes that makes the genome dynamic agents of life instead of a determining blueprint, thus demonstrating his strength as an observational scientist $[37,38]$.

\section{Matter as structured energy}

".... the existing scientific concepts cover always only a very limited part of reality, and the other part that has not yet been understood is infinite."

Werner Heisenberg [39]

Smuts' interest in different scientific fields kept him updated in the development of science, while his photographic memory and ability for synthesis [25] gave him the intellectual power to grasp areas outside his own specialised fields of politics and botany. It seems that Einstein's theory of relativity struck a chord of recognition and gave him a way to describe his own ideas about wholeness. Smuts claims that when quantum physics based on Einstein's theories are transferred to matter the impression of static structures must by necessity be changed. Smuts expressed his interpretation of Einstein's theories of the construction of reality as "Matter is thus a structure of energy units revolving with immense velocities in Space-Time, and the various 
elements arise from the number and arrangement of the units in an atom" [11]. The impression of matter as stationary is an illusion, as it instead is intensely active and when Smuts writes "Matter itself is nothing but controlled structural energy, energy stereotyped into structure" he is explaining Einstein's formula $E=m c^{2}[11]$.

According to Smuts, matter is a mass of active pulsating energies equivalent to the activities of quantum particles or waves, a hypothesis similar to Esfelds' proposition of 'quantum holism' [40]. As modern quantum science can still not be transferred to the realm of organic matter, this hypothesis cannot yet be verified. If it is verified, it will form one of the pieces needed to transform the paradigm of positivistic reductivism into a more complex paradigm based on nonlinear systems.

The concept of fields

The next step in Smuts' theory of holism is the introduction of fields, extending the active energy system of matter beyond the physical structure of all organisms. The perceivable part of matter is described as a narrow observable part and radiating outwards from it is "the dark 'field' which is formed by the activities and properties of the thing beyond its sensible focal centre" [11]. According to Smuts, these invisible "Fields of force" contains all experiences of each individual organism and strives towards its continuous evolutionary development. To limit organisms to their physical structures is a distortion of their real character that "has to be rid of at all costs" [11]. The concept of individual fields of energy contained within space-time, re-evaluates matter from a finite static structure to instead become a dynamic part of the field made visible by controlled structural energy. From the limited material dimension, it depicts the nature of reality as invisible fields surrounding the small part of perceivable matter. Enveloped in the field is the wholeness of time for each organism, representing the past, present and to a smaller extent the future.

When the full extent of time is viewed as part of the wholeness, the powerful influence of past experiences becomes significant. The voice of the subconscious part might not speak, "but it votes, and its silent voice is often decisive", thus integrating memories from the past with actions of the present [11].

In quantum physics, it has turned out that not only is the introduction of fields necessary to explain the fundamental laws of nature for particles, but that the field is the primary source and not the particles in themselves $[40,41]$. This must be compared with Smuts' statement that "It is 
in these fields and these fields only that things really happen" [11]. In his Nobel acceptance speech in physics, presenting the findings behind the accelerating expansion of the Universe, Adam Reiss points to three possible explanations, one of them being a field with dynamical dark energy pervading space [42]. Dark matter is also explained as an invisible field, but as science is only starting to explore the phenomena no conclusions can yet be made [43]. The development in physics might in due time verify that Smuts did perceive a reality few others could grasp at that time.

\section{Time and Space-Time}

Smuts refers to Minkowski's original idea presented in 1908 introducing time as a new dimension, thus combining space and time into space-time, which Einstein continued to develop into the General theory of relativity presented in 1915. The theory clarifies that both space and time are relative and depend on both the position of the observer and the speed of the object, as neither exist independently of the other. Smuts stresses the fusion of space and time into one synthesis as a highly important achievement for science as well as philosophy. In this way, space-time will become a part of physical reality and explains the field as a definite structure of its own, integrating time with the spatial conception of the perceivable world. In line with Smuts' explanation of how the theory of relativity must change the general philosophical view, Crotty describes the epistemological and ontological change inflicted by the uncertainty principle of quantum physics, changing the positivistic fact of verification by observation into theories relaying on "mere heuristic and explanatory devices" concerning particles and fields [44]. According to Smuts' theory the in-cooperation of space-time as a part of reality implies that all organisms have the totality of time, including their own evolutionary development, as a part of the framework in their individual fields. In this way, the field becomes an active part of matter coordinating the activities for the evolutionary development of each individual whole.

\section{Mind as a new field}

Smuts' presentation of his theory in the earlier chapters of his book describes the evolutionary process as rising series of continuing development of wholes, from atoms to cells and further on to cooperating cells in higher developed organic structures, but in the explanation of mind he diverges from a single line continuation and instead presents two roots:

1. A continuation of the system of organic regulation.

2. A new whole imposing a fresh start toward individuality. 
Smuts struggles with the mind and never manages to achieve a reasonable explanation. These contradictions point to weak spots in the theory. As the physiological aspects of organic regulations "surpasses anything our ingenuity can understand or encompass", while the mind is described as a new and still not totally successful experiment of the universe, Smuts' conclusion is that the mind is a fresh start instead of a direct continuation and development of the organic regulations [11]. He describes the mind as a "new kind of structure of the immaterial or spiritual kind, and so also is its field", but contradicts himself with the explanation "as the brain is merely a development of the nervous system, so the Mind is nothing but a development of prior organic regulation" [11]. The description of the origin of mind following an evolutionary continuation of organic development is clear and in accordance with the theory. The first step being an inward attention towards a sense of discomfort due to a disturbance of equilibrium, followed by the ability to remove the strain which creates a sense of ease. The rise of an evolving consciousness forms the first steps in the creation of mind and exists as a double aspect with both an inner awareness of strain and an outward-facing assimilation of external objects. Smuts writes that the formulation for mental experiences is "The Subject - conscious of - an object", thus splitting up experiences in a duality [11].

The breaking point

The process of evolution moves from organic mass systems towards higher levels of individuation and Smuts ascribes the human level as a new departure from the old regular building of structures, due to the introduction of the mental ability for individual perceptions of reality. This forms the breaking point in the theory where Smuts is forced to introduce, what he in fact despises as it is not based on reason, a "deus ex machina" or the plot device that will suddenly solve an unsolvable problem, to save his line of arguments following the second suggested root of mind. He is not introducing a new concept like entelechy, vital force or the interception of God, which is the usual meaning of the expression. Instead the foundation off the new whole is left unanswered until the last chapters where the origin is briefly explained as a "new mutation or series of mutations" [11]. Smuts criticises scientists explaining evolution by random mutations as it denies the creative action of nature in the process, but now he uses the same explanation himself. To be unable to explain the origin of what Smuts describes as the most advanced step in evolution, so advanced that it only involves humanity, indicates a probable flaw in the theory. 
Alternatively, to follow the more trustworthy line of an organic evolution slowly developing into higher organisms with individual consciousness and unique minds leaves no option other than the acceptance of an evolved system of mind in all developed species of animals. This will dethrone humanity from a singular position in evolution and Smuts was either not ready to take this step or could not perceive where the logical conclusion of his own theory would lead. To make the leap solves the problem with having two different origins for the mind, which is not in accordance with the theory in general.

\section{Personality}

The lack of a logical continuity is reinforced when he presents personality as the last and most advanced step in evolution. The description of yet another new whole, with the same weakness in explaining the source as the second root of mind, makes the contradictions so strong that by now it is impossible to accept this part of the theory as reasonable. Smuts might have seen the weakness, describing the personality as a mystery, but he still continues along the same track to be able to place personality as a unique human mental and spiritual quality. The contradictions also continue, and personality is in one place described as "a new structure built on the prior structures of matter, life and mind", coming closer to a biological view on evolution with a bottom-up perspective, while on the next page he writes that it "marks a new and fundamental departure in the evolution of the universe" [11].

Still, Smuts' undoubted strength in synthesising parts into wholeness continues to bring advanced and interesting views on both the psychological system of humanity and views of reality, forming the double aspects of the theory. Although in the main, psychologists adhered to the reductive model of science as a way to become scientifically accepted, both Adler's Individual psychology and Perl's Gestalt therapy refer to Smuts' holism as one source for their ideas [45]. Adler became so impressed by 'Holism and Evolution', that he recommended his students to read the book and initiated a German translation of it [46]. His concept of integrating the wholeness of the patient's psychosocial environment in the treatment resonate to an extent with Smuts description of holism. When Fritz and Laura Perl lived in South Africa during the second world war they were introduced to 'Holism and Evolution' and Smuts' holism is accounted as one important source for Gestalt therapy's view of the individual as a whole including mind, thoughts and imagination as well as body and movements $[45,47]$. 


\section{A hierarchical view on personality}

It is open to question as to why Smuts deemed it necessary to depart from his former description of a systematic continuation of organic development. The answer appears to lie in the concept of humanity holding a place above all other species in the universe. The following quote describes the heart of the matter:

"As Nature finally learns to read herself with the human eyes which are her own, so through the human Self which is the highest and best it has yet come to, Holism may gaze back to its beginnings and scrutinise what would otherwise be dark and unintelligible for ever." [11]

Smuts' hierarchical view of reality begins to unfold in the chapter presenting mind and when he later presents personality, it becomes consistent. The field of personality, systematically described as a 'human personality', is denied to all other species. The former states of organic evolutionary development are described as having a dominant mechanistic aspect, and for this reason individual differences between animals or plants "are generally considered negligible, and one individual is for purposes of scientific treatment as a rule the same as any other individual' [11].

Smuts asks how the field of a material body can interact with the immaterial or spiritual kind of field constituting the mind, and finds it inconceivable, as they are of such different qualities. Later he contradicts himself by stating that a "disembodied Mind and disminded Body are both impossible concepts" [11]. The contradictions continue when he presents the second new field representing personality "built on the prior structures of matter, life and mind", being both spiritual and organic at the same time [11].

He states that from a biological view personality is simply the highest level of an ascending series of developments and not a unique and new part of evolution that raises it "infinitely above the merely animal phases", accomplishing a transformation of the whole universe by the act [11]. As the existence of fields in developed organisms is still not validated by science, Smuts' belief of fields having different qualities is not based on facts. Instead it is based on old philosophical and religious concepts dating from Greek philosophy and Christian doctrines [48].

To enable humanity to become the master not only over animals but also nature, in line with the strong paradigm of western society based on Christian values and reinforced by the rational Enlightenment period and Cartesian dualism, Smuts had to exclude the field of personality from all other species $[27,39,49,50]$. Smuts' belief in humanity as the superior species in the universe 
underpins his definition of personality and higher states of mind as solely human fields. The creation of metaphysical anthropocentric theories, legitimating the illusion of a central position for humanity in the universe, belongs to earlier scientific ideals in fashion before the 1900s [50]. In view of knowledge arising from modern science in astrophysics, the medieval thought of humanity being the centre of universal creation seems thoroughly outdated, although the anthropocentric paradigm is still debated [51,52]. When Crotty states that the world "becomes a world of meaning only when meaning-making beings [human species] make sense of it" he describes an anthropocentric view [44].

Smuts' opinion concerning the necessity of a hierarchical order holds a central position when explaining the contradictions in the theory. To understand his reasoning, it is necessary to understand his political view. In politics Smuts was mainly aligned with liberal imperialism, but also with the belief in the superiority of the progressive white civilizations of Europe through the increasing rational perspective of reality $[25,26]$. Smuts had no objections to giving supreme control to one single part of the wholeness, and compared personality to an organised state "with its central executive and legislative authority wielding sway over its individual members in the interest of the whole" [11]. The explanation for the top-down perspective in the theory of holism is based on a political and philosophical rather than a scientific view on reality. Smuts' view does not belong in a scientific presentation and might be the major reason why the theory never gained scientific acceptance.

\section{Top-down or bottom-up perspective?}

"My object in this chapter is solely to shew that there is no fundamental difference between man and the higher mammals in their mental faculties."

\section{Charles Darwin [53]}

While Smuts on one hand introduce wholes as a fundamental aspect of the universe in accordance with space-time and criticises the mechanistic view of scientists, on the other he still holds on to the old philosophical roots of the western civilisation in the theory. In accordance with Cartesian dualism, bodies are described as mechanistic and only humans have the more developed fields of mind and personality, not only because they include higher cognitive abilities, but also the spirit. In this case, it is partly Smuts knowledge in philosophy combined with his Christian belief that contributes to the problem. He is well versed in philosophy, arguing against 
other theories of reality in 'Holism and Evolution', but at the same time stuck in the old perception of body and spirit being two different entities, and for this reason is unable to follow the logic of his own theory. If the field is supposed to be not only a major part of organisms, but the place where "things really happen", then the spirit will be equivalent to the field, which is in accordance with the theory [11]. The only logical reason for deeming it necessary to introduce two new wholes, lacking a reasonable explanation for their foundation, is Smuts' hierarchical perception and his adherence to the religious concept of the spirit as a solely human factor. It is not possible for Smuts to perceive reality from the biological point of view, as this would force him to either deny the existence of the spirit or accept that all living beings with consciousness have personalities and spirits. To combine the evolutionary development of fields with the biological point of view leads to a pantheistic view of reality, a totally unacceptable conclusion for Smuts [9,25,54]. A second problem for Smuts is that a biological continuation of evolution will remove humanity as the dominant species topping the hierarchical ladder. Humanity will instead become one species among others, although still with highly developed cognitive abilities. The change will form a non-hierarchical view of reality with focus on individual stages of evolutionary development.

Although 90 years have passed since the theory was published, the debate about the difference between humans and animals is not settled and continues to be a controversial subject $[55,56]$. According to de Wall and Ferrari the biological view of continuity in the development of anatomy, neuroscience and genetics is widely accepted, while the area of cognition continues to be debated [55]. More sophisticated trial methods testing cognitive abilities in animals, combined with results in social psychology, have contributed to a change of view during the last decade. Instead of an anthropomorphic (attributing human characteristics to animals) explanation, as it is "not always correct even for humans", focus is placed on the similarities between humans and animals in cognitive solution processes, thereby emphasising the animal-likeness in humans [57]. This model implies a continuous evolutionary development or a bottom-up perspective in accordance with the biological point of view. It is contradictory to Smuts' anthropocentric or topdown perspective.

To establish a credible foundation for the view of mind and body as one whole organism, and by doing so remove the old Cartesian concept of a mind-body duality in a more profound way, it seems that the question of the evolutionary development of cognitive aspects must first be settled. Is the correct solution concerning evolution an anthropocentric or top down perspective or is it instead the view originally described by Darwin, the bottom-up development $[35,58,59]$ ? 
Unfortunately, Smuts' presentation of the theory rather confirms the old structures instead of creating a new and fresh perspective on the matter. It is at the same time a question of following a logical continuation through the theory. Smuts states that the beginning of mind is consciousness of internal and external strains, followed by a sense of relief when the strain is removed. This description of consciousness will include all animals and is according to the theory a continuation of the evolutionary steps of organic matter. It is also in line with established data concerning simple forms of associated learning based on memory found in all tested species, including invertebrates [57]. For this reason, Smuts' introduction of two radically new wholes, a higher state of mind and personality solely in humans, only briefly referring to their origins as mutations, is not good enough and jeopardizes the whole theory.

Internal vs external aspects of the personality

"I am my world."

Ludwig Wittgenstein [60]

The split between logic and illogical conclusions in the theory, and between a description of the ultimate aim of evolution as either a self-controlled superior personality or a relaxed, sincere and creative individual, reflects the double nature of Smuts [21,22,25]. Hancock, who worked 15 years before publishing his biography of Smuts, struggled to piece together the different sides of him [23]. The personality of Smuts is not easy to grasp and must be seen not as divided into two but three parts; the pragmatic calculating politician with a strong hierarchical perception of reality, the gifted natural scientist and the spiritual bible reading philosopher looking towards Jesus for guidance. In the sections above the gifted natural scientist and politician Smuts has dominated, but when analysing his description of the inner qualities of personality it is the spiritual philosopher that comes forward.

According to Smuts, not only time but also reality is relative. The following quote describes what today is known as the paradigm of constructivism;

"The world in experience is at the bottom my reading of the world in which I am the centre reference, where the system of co-ordinates of measurement is my private system; and the space, time and experience which go to the making of it are my space, 
time and experience. Objectivity and universality are indeed attainable, but only from a subjective and individual starting point and centre of reference. Individuation is bound up with reality on the psyche plane" (emphases in original) [11].

The quote can be compared with how Guba explains constructivism

"One immediate consequence is that I recognize that what I am about to say is my own construction, not necessarily an objective (whatever that may be) analysis." [61]

According to Guba the constructivist paradigm describes an ontological position of relative realities existing "in the form of multiple mental constructions" [61], but although this matches what Smuts wrote 64 years earlier, the theory of holism also claims that the ultimate goal for the personality "does not lie outside it but is given inwardly" [11]. A stimulus from the environment can only influence indirectly after the organism or individual has internalised it, as it transforms during the process. Through evolution, the inner capacity of attention and assimilation combined with the choice of reaction "continues to grow in its double inner and outer aspects" and "pursues the double task of self-protection and perfection of All" [11].

What Smuts writes is that the main influence of evolution is not external but internal, as it is individual abilities to handle everyday choices that determines the quality of life and forms the aim of the whole. Holism is about self-realisation of the whole by evolution. This mirrors closely Roger's theory of how the development of the mature person is based on evaluating inner experiences during the life process [62]. To achieve the desired tranquillity, the buzzing of daily life must be stilled to let the "small voice of inner life" come forward as this is the way to "learn to be yourself with perfect honesty, integrity and sincerity;" [11]. Slowly the selfishness is curbed and subdued with other motives, allowing a more complete view of reality to be formed.

To change the perception of evolution from an external to a mainly internal process will accomplish a significant shift that will have profound effect on society if it was accepted. In line with constructivism and biological systems theories, it places the determining factors of life on our individual abilities to live a sustainable life in balance with both ourselves and our surroundings. The level of resilience against external stressors will be determined by the intrinsic evolutionary process of each individual whole. In this way, the effort to live a balanced and healthy life will become a part of the whole life process. 


\section{Conclusion:}

The first part of the Theory of Holism, concerning wholes, matter, fields and space-time is in view of contemporary science still advanced and constitutes a possibility for explaining the reality of nature, but must wait for science to develop further to be validated. The concept of fields is today accepted as a probable explanation behind the action of particles with short distance gravitational effects in quantum physics $[40,41]$. For modern physics, including astrophysics, Einstein's theories work well concerning macroscale objects with gravitational long-distance effects, but so far science cannot combine the two areas with each other [40]. The first step in the theory, accepting matter as structured energy, is in accordance with quantum physics and so is the action of fields, while astrophysics is moving towards fields being one probable explanation for the 95 percent of the universe consisting of dark energy and dark matter. Although, Smuts' description of fields must be divided into two parts where the possibility for the existence of fields has a high probability, while grading fields in accordance with a hierarchical perception of evolution has a lower credibility. Smuts' suggestion concerning three different wholes representing the body, cognitive abilities of mind and individual personality can be debated as it is based on his anthropocentric view.

The second part of the theory of holism, describing the evolution of the more advanced states of mind and personality, consists of too many contradictions and does not follow the logical assumptions presented earlier in the theory. For this reason, it must be considered as flawed. As it still contains interesting aspects, crucial for developing an understanding of wholes, it cannot be dismissed as an unimportant part of the theory. In particular, the effect of individual internal reactions to external stressors, which possibly affect lifestyle choices as well as emotional responses, holds a potential to contribute important aspects for the development of systems models in medicine and healthcare.

Based on the overall values of the theory of holism, the recommendation is to rework the second part of the theory. The concept of wholes can also be developed further by integrating contemporary science in the fields of physics, biology, psychology and social sciences. If this is accomplished the theory might have the ability to further progress the development of complex systems theories.

Hence the authors suggest the following new definition of holism: 


\section{Proposition for a new definition of holism}

Holism constitutes an evolutionary development transforming individual wholes into new states through a mainly internal process. Each step creates a change of equilibrium altering the potential for sustainability. Individual abilities of self-maintenance and adaptability concerning the impact of mental, social and environmental stressors determine the progress of evolution.

\section{Declaration of interest:}

All research done by the authors.

Financial support: no. This research did not receive any specific grant from funding agencies in the public, commercial, or not-for-profit sectors.

Conflict of interest: none

The article is based on the researcher's work in partial fulfilment of the degree MSc Integrated Healthcare from the University of Central Lancashire. Dr Hazel Partington is a senior lecturer at the University of Central Lancashire.

\section{competing interests}

Chris Jörgenfelt: None

Hazel Partington: None

\section{sources of funding}

Chris Jörgenfelt: None

Hazel Partington: None 


\section{References}

[1] M. Esfeld, Holism in Cartesianism and in today's philosophy of physics, J. Gen. Philos. Sci. 30 (1999) 17-36. doi:10.1023/A:1008326613673. p. 17.

[2] Tauber A. I., The Ethical Imperative of Holism in Medicine, in: M.H. V. Van Regenmortel, D.L. Hull (Eds.), Promises Limits Reductionism Biomed. Sci., John Wiley and sons, Ltd., Chichester, 2002. doi:org/10.1002/0470854189.ch13.

[3] S. Woods, Holism in health care: Patient as person, in: T. Schramme, Edwards S. (Eds.), Handb. Philos. Med., Springer International Publisher, New York, 2017. doi:10.1007/978-94-017-86881_21.

[4] F. Conti, M.C. Valerio, J.P. Zbilut, A. Giuliani, Will systems biology offer new holistic paradigms to life sciences?, Syst. Synth. Biol. 1 (2007) 161-165. doi:10.1007/s11693-008-9016-1.

[5] J. Freeman, Towards a definition of holism., Br. J. Gen. Pract. 55 (2005) 154-5. http://www.ncbi.nlm.nih.gov/pubmed/15720949\%0Ahttp://www.pubmedcentral.nih.gov/articler ender.fcgi?artid=PMC1463203.

[6] A. Givati, Performing 'pragmatic holism': Professionalisation and the holistic discourse of nonmedically qualified acupuncturists and homeopaths in the United Kingdom, Heal. (United Kingdom). 19 (2015) 34-50. doi:10.1177/1363459314530739.

[7] P. Pietroni, Is complementary medicine holistic?, Complement. Ther. Nurs. Midwifery. 3 (1997) 911. doi:10.1016/S1353-6117(97)80027-3.

[8] D.T. Wade, Holistic Health Care What is it, and how can we achieve it?, 2009. https://www.google.se/search?q=Wade\%2C+D.+T.+\%282009\%29.+Holistic+health+care.+What+i s+it\%2C+and+how+can+we+achieve+it\%2C+Oxford+Centre+for+Enablement\%2C+209.+\&ie=utf$8 \& o e=u t f-8 \& c l i e n t=f i r e f o x-b-a b \& g f e \_r d=c r \& d c r=0 \& e i=7$ lgqWuGSJ4-D3AOtwZbIDA.

[9] D. Gatherer, So what do we really mean when we say that systems biology is holistic?, BMC Syst. Biol. 4 (2010). doi:10.1186/1752-0509-4-22.

[10] G. Járos, Holism Revisited: Its Principles 75 Years On, World Futures. 58 (2002) 13-32. doi:10.1080/02604020210400.

[11] J.C. Smuts, Holism and Evolution, The Macmillan Company. Reprinted by Kessinger Publisher, MT., New York, 1926. pp. 50, 99, 86, 131, 135, 35, 51, 112, 18, 111, 254, 18, 231, 253, 244, 238, 320, 261, 262, 293, 278, 261, 261, 274, 290, 18, 240, 315, 243, 314, 315.

[12] R. Whittemore, K. Knafl, The integrative review: Updated methodology, J. Adv. Nurs. (2005) 546553. doi:10.1111/j.1365-2648.2005.03621.x.

[13] R.J. Torraco, Writing Integrative Literature Reviews: Guidelines and Examples, Hum. Resour. Dev. Rev. 15 (2005) 404-428. doi:10.1177/1534484305278283.

[14] C. Russell, An overview of the integrative research review, Prog. Transplant. 15 (2005) 8-13. doi:10.7182/prtr.15.1.0n13660r26g725kj.

[15] R.J. Torraco, Writing Integrative Literature Reviews: Using the Past and Present to Explore the Future, Hum. Resour. Dev. Rev. (2016). doi:10.1177/1534484316671606. 
[16] P. Cronin, F. Ryan, M. Coughlan, Undertaking a Literature Review, Br. J. Nurs. 17 (2008) 38-43. doi:10.1177/107808747000500401.

[17] A. Bowling, Research methods in health: investigating health and health services, Open University Press, Buckingham, 1997.

[18] H.F. Hsieh, S.E. Shannon, Three approaches to qualitative content analysis, Qual. Health Res. 15 (2005) 1277-1288. doi:10.1177/1049732305276687.

[19] R. Ritchie, J., Lewis, J., Nicholls, C. M., \& Ormston, Qualitative research practice: a guide for social science students and researchers, Sage, Los Angeles, 2014.

[20] V. Clarke, V. Braun, Successful Qualitative Research: A Practical Guide For Beginners, Sage, London, 2013.

[21] R. Engels, Jan Smuts and Walt Whitman: strange bedfellows, Safundi. 17 (2016) 339-356. doi:10.1080/17533171.2015.1125605.

[22] S. Marks, White masculinity: Jan Smuts, race and the South African war, in: Proc. Br. Acad., 2001: pp. 199-224.

[23] K. Tsokhas, A Search For Transcendence: Philosophical And Religious Dialogues In W. K. Hancock's Biography Of J. C. Smuts, Round Table. 90 (2001) 67-88. doi:10.1080/003585301225295.

[24] N.B. Harte, The University of London, 1836-1986: An illustrated history, The Athlone Press, London, 1986.

[25] S. Dubow, Smuts, the United Nations and the rhetoric of race and rights, J. Contemp. Hist. 43 (2008) 45-74. doi:10.1177/0022009407084557.

[26] P. Anker, Imperial Ecology Environmental Order in the British Empire, 1895-1945, Harvard University Press, Cambridge, 2002.

[27] J. Kochanek, Jan Smuts: Metaphysics and the League of Nations, Hist. Eur. Ideas. 39 (2013) 267286. doi:10.1080/01916599.2012.732298.

[28] C.L. Morgan, Holism and Evolution by J. C. Smuts [Review], J. Philos. Stud. 2 (1927) 93-97. https://www.jstor.org/stable/3745387.

[29] F.W. Brush, Jan Christian Smuts and His Doctrine of Holism, Ultim. Real. Mean. 7 (2018) 288-297. doi:10.3138/uram.7.4.288.

[30] J.C. Smuts, Contributions to a British Association Discussion on the Evolution of the Universe, Nature. 128 (1931) 718-719. https://www.nature.com/articles/128718a0.

[31] G.J. Kerr, Evolutionary Philosophy (review Holism and Evolution), Nature. 119 (1927) 307-309. doi:10.1038/119307a0.

[32] K. Popper, The Poverty of Historicism, Routledge, Abingdon, 1957.

[33] L. Von Bertalanffy, The history and status of general systems theory, Acad. Manag. J. 15 (1972) 407-426. doi:10.2307/255139.

[34] A.C. Ahn, M. Tewari, C.S. Poon, R.S. Phillips, The limits of reductionism in medicine: Could systems biology offer an alternative?, PLoS Med. 3 (2006) 0709-0713. 
doi:10.1371/journal.pmed.0030208.

[35] P.A. Corning, The re-emergence of emergence, and the causal role of synergy in emergent evolution, Synthese. 185 (2012) 295-317. doi:10.1007/s11229-010-9726-2.

[36] J.P. Sturmberg, "Returning to Holism": An Imperative for the Twenty-First Century, in: J.P. Sturmberg (Ed.), Value Syst. Complex. Sci. Healthc., Springer International Publishing, New York, 2016: pp. 3-19. doi:10.1007/978-3-319-26221-5_1.

[37] L. Getz, A.L. Kirkengen, E. Ulvestad, Menneskets biologi - mettet med erfaring, Tidsskr. Den Nor. Laegeforening. 7 (2011) 683-687. doi:10.4045/tidsskr.10.0874.

[38] P. Jensen, Transgenerational epigenetic effects on animal behaviour, Prog. Biophys. Mol. Biol. 113 (2013) 447-454. doi:10.1016/j.pbiomolbio.2013.01.001.

[39] W. Heisenberg, Physics and Philosophy. The revolution in modern science, Harper \& Bros, New York, 1958. p. 141

[40] M. Esfeld, Physicalism and ontological holism, Metaphilosophy. 30 (1999) 319-337. doi:10.1111/1467-9973.00141.

[41] D. Tong, Lectures on Quantum Field Theory, Part III Mathematical Tripos., 2006. http://www.damtp.cam.ac.uk/user/tong/qft.html.

[42] A.G. Reiss, Nobel Lecture by Adam G. Riess, (2011). https://www.nobelprize.org/mediaplayer/index.php?id=1729.

[43] S. Carroll, Particles, Fields and The Future of Physics - A Fermilab Lecture by Sean Carroll, YouTube. (2013). https://www.youtube.com/watch?v=gEKSpZPByD0 (accessed October 15, 2018).

[44] M. Crotty, The foundations of social research: meaning and perspective in the research process, 2015th ed., Sage Publications, London, 1998. p. 10, 30.

[45] C. Shelley, Jan Smuts and Personality Theory: The Problem of Holism in Psychology, in: R. Diriwächter, J. Valsiner (Eds.), Striving Whole Creat. Theor. Synth., Routledge, Abingdon, 2008: pp. 103-124. http://search.library.utoronto.ca/details?6440809\&uuid=81745362-d5c4-4a5d-9dfc3d6979bb6e93.

[46] L.J. Nicholas, Early South African engagement with international psychology, South African J. Psychol. 43 (2013) 289-299. doi:10.1177/0081246313494569.

[47] L.E. Wagner-Moore, Gestalt Therapy: Past, Present, Theory, and Research, Psychother. Theory, Res. Pract. Train. 41 (2004) 180-189. doi:10.1037/0033-3204.41.2.180.

[48] H. Lorenz, Ancient Theories of the Soul, Stanford Encycl. Philos. (2009). https://plato.stanford.edu/archives/sum2009/entries/ancient-soul/ (accessed November 28, 2018).

[49] P. Adinolfi, Philosophy, medicine and healthcare: Insights from the italian experience, Heal. Care Anal. 22 (2014) 223-244. doi:10.1007/s10728-012-0208-1.

[50] D. Harvey, The condition of postmodernity: an enquiry into the origins of cultural change., Blackwell, Oxford, 1990. 
[51] E. Domanska, Anthropocentrism in Philosophy, Historein. 10 (2011) 118-130. https://www.google.com/search?client=firefox-b-ab\&biw=1134\&bih=495\&ei=6YnW4D_FtCHwPAPyI2nqAo\&q=Domanska\%2C+ewa\%2C+Anthropocentrism+in+Philosophy\%2C+hist orein\&oq=Domanska\%2C+ewa\%2C+Anthropocentrism+in+Philosophy\%2C+historein\&gs_l=psyab.3...194651.219965.

[52] A. Wietzenfeld, M. Joy, An overview of anthropocentrism, humanism, and speciesism in critical animal theory, in: \& M. Nocella II, Sorenson, Socha (Ed.), Defin. Crit. Anim. Stud. an Intersect. Soc. Justice Approach Lib., Peter Lang Publisher, New York, 2014: pp. 3-27.

[53] C. Darwin, The descent of man, J. Milhoff \& Co, London, 1871. p. 35

[54] S. Strijbos, Systems Thinking, in: M. Frodeman, Klein (Ed.), Oxford Handb. Interdiscip., Oxford University Press, New York, 2010.

[55] F.B. de Waal, P.F. Ferrari, Towards a bottom-up perspective on animal and human cognition, Trends Cogn. Sci. 14 (2010) 201-207. doi:10.1016/j.tics.2010.03.003.

[56] S.J. Shettleworth, Darwin, Tinbergen, and the Evolution of Comparative Cognition, in: Oxford Handb. Comp. Evol. Psychol., 2012: pp. 1-18. doi:10.1093/oxfordhb/9780199738182.013.0028.

[57] S.J. Shettleworth, Clever animals and killjoy explanations in comparative psychology, Trends Cogn. Sci. 14 (2010) 477-481. doi:10.1016/j.tics.2010.07.002.

[58] de Wall.F. B., Darwin's last laugh, Nat. . 460 (2009) 175. doi:10.1038/460175a.

[59] J. Mallet, Why was Darwin's view of species rejected by twentieth century biologists?, Biol. Philos. 25 (2010) 497-527. doi:10.1007/s10539-010-9213-7.

[60] L. Wittgenstein, Tractatus Logico-Philosophicus, Routledge \& Kegan Paul, London, 1961. p. 57.

[61] E. Guba, The Alternative Paradigm Dialog, Sage Publication, Newbury Park, CA, 1990. p. 17, 27.

[62] C.R. Rogers, Toward a modern approach to values: The valuing process in the matured person, in: T.M. Covin (Ed.), Readings Hum. Dev. A Humanist. Approach, MSS Information Corporation, New York, 1974: pp. 75-82.

https://books.google.se/books?hl=sv\&lr=lang_en\&id=wmxZlaW03QkC\&oi=fnd\&pg=PA75\&ots=RE 2vc2bhvZ\&sig=Hqp8YT8IhRnqE2U_jweC3C8LmEs\&redir_esc=y\#v=onepage\&q\&f=true. 